\title{
Малицька Ірина Дмитрівна
}

старший науковий співробітник Відділу компаративістики інформаційно-освітніх інновацій Інститут інформаційних технологій і засобів навчання НАПН України, м. Київ, Україна

Irina_Malitskaya@mail.ru

\section{ВИСОКИЙ РІВЕНЬ ІК-КОМПЕТЕНТНОСТІ ВЧИТЕЛЯ - ЗАПОРУКА ЦИФРОВОЇ ГРАМОТНОСТІ УЧНІВ (ДОСВІД ВЕЛИКОЇ БРИТАНІї)}

\begin{abstract}
Анотація. У статті розглядаються підходи до оцінювання ІК-компетентності вчителя, адміністратора та директора школи Великої Британії. Зазначається, що процес оцінювання спирається на державні освітні стандарти, регулюючи документи, а також «Модель для атестації штату i політики 3 професійної кваліфікації школи», що розроблена i рекомендована освітніми інституціями разом з Департаментом освіти Великої Британії. Описані методи оцінювання ІК-компетентності вчителя, а також найбільш визнані інструменти: Atomic Learning, Future Learn, TES Global, мережі Computer at School i Network of Excellence.
\end{abstract}

Ключові слова: інформаційні і комунікаційні технології; ІК-компетентність; учитель; директор школи; оцінювання; система освіти Великої Британії; зарубіжний досвід.

\section{1. ВСТУП}

Постановка проблеми. Набуття i розвиток навичок 21-століття, цифрова грамотність, розвиток Цифрової Європи задекларований у Цифровому плану дій для Європи (Digital Agenda for Europe) [3] залежить від якісного навчання учнів і студентів, яке можуть здійснювати тільки висококваліфіковані спеціалісти. Для досягнення поставлених цілей рівень підготовки вчителів має відповідати сучасним вимогам i викликам суспільства. Зважаючи на те, що у країнах Європейського Союзу існує більш ніж 28 різних систем підготовки вчителів, Свропейський парламент у своїй резолюції стосовно підвищення якості педагогічної освіти визначив спільні проблеми, які стосуються всіх держав-членів СС. У резолюції були надані 36 пропозицій поданих Раді й Комісії ЄС, державам-членам ЄC, OECD, ЮНЕСКО та у Раду Свропи, ключовими 3 яких є: підвищення якості освіти вчителів, шляхом залучення кращих кандидатів для роботи у міністерствах, державних освітніх установах; сприяння постійному та послідовному професійному розвитку вчителів протягом всієї їхньої кар'єри; можливості для всіх вчителів регулярно оновлювати свої навички і кваліфікації (наголошено, що кваліфікації повинні бути визнані всіма країнами-членами ЄС); необхідність у транснаціональному обміні досвідом; надання особливої уваги до введення в професію вчителів-початківців; удосконалення програм з наставництва; формування та розвиток критичного мислення вчителів; підвищення рейтингу професії вчителя [1].

Система освіти Великої Британії у процесі впровадження освітньої реформи 2014 року, спрямованої на підвищення рівня ІК-компетентності практично всього населення країни, підвищення мотивації учнів, студентів до поглибленого опанування інформаційними технологіями, програмуванням, зіштовхнулася 3 недостатньою підготовкою вчителів, які б сформували в учнів відповідні вміння та навички.

Огляд, який був проведений у квітні 2016 року щодо вміння вчителів використовувати IКT у навчальному процесі, показав, що практично половина опитуваних вчителів не використовують технології у процесі викладання. Причиною такого стану є незадовільна підготовка самих вчителів до використання IКТ, а також 
незадовільний стан технічного оснащення шкіл, відсутність їх підключення до інтернету. Як у початковій, так і у середній школі вчителі не знають як краще інтегрувати IКТ у навчальні плани і програми. Було виявлено, що 50\% вчителів державних навчальних закладів визнають свою неготовність щодо використання IКТ, порівняно з учителями, які працюють у приватних школах (43,9\%) [2].

3 огляду на це, підготовка, перепідготовка вчителів щодо інтегрування інформаційних технологій у процес викладання свого предмету, мотивація щодо підвищення рівня своєї ІК-компетентності стала однією 3 основних проблем над вирішенням якої працюють освітяни, державні освітні структури Великої Британії.

Аналіз останніх досліджень і публікацій. Оцінювання ІК-компетентності вчителів, директорів та адміністрації шкіл залишається однією з актуальних тем, яка обговорюється на національному і міжнародному рівнях освітянами різних країн світу. Форми, методи та інструментарій оцінювання значно залежить від освітньої політики країни, процесів реформування, освітніх стандартів, затверджених навчальних планів i програм, рівню яких повинна відповідати ІК-компетентність штату школи.

Країни Свропи, у тому числі і Велика Британія, у проведенні освітніх реформ керуються такими основоположними міжнародними документами як: Стратегічна рамка ЄС з освіти і підготовки 2020 (EU's Strategic Framework for Education and Training 2020) [3], Цифровий план дій для Свропи (Digital Agenda for Europe) [4], Рекомендації Європейського Парламенту і Ради („Ключові компетентності для навчання упродовж життя” 2006 (Key Competences for Lifelong Learning, 2006) [5], „Свропейська рамка кваліфікацій для освіти упродовж життя" (European Qualifications Framework for Lifelong Learning, 2008) [6] та інші.

Проблеми впровадження IКT у навчальний процес школи, відповідність підготовки вчителя до інтегрування інформаційних технологій у професійну діяльність вивчають такі вчені Великої Британії як: Дж. Брунер, В. Дойс, С. Хенесі, С. Кенвел, Л. Ньютон, Л. Роджерс, Л.Сюзерленд та інші.

Професійній освіті і підготовці вчителів у Великій Британії присвячені роботи таких вітчизняних науковців як: М.П.Лещенко, О.I Локшина, Л.П.Пуховська, А.В.Парінов, С.І.Синенко, Ю.В.Кіщенко, Н.М.Авшенюк.

Оцінювання інформаційно-комунікаційної компетентності $\epsilon$ предметом дослідження таких вітчизняних (Биков В. Ю., Морзе Н. В., Лукіна Т. О., Ляшенко О. І., Жук Ю.О., Жалдак М.І., Спірін О. М., Овчарук О.В., Литвинова С. Г. та ін.) і зарубіжних (Г. Айзенк, С. Берт, К. Гіпс, Д. Уільям та інші) учених.

Метою статті $є$ проаналізувати і визначити підходи, методи та інструментарій, які використовують у школах Великої Британії для оцінювання ІК-компетентності вчителів та адміністраторів шкіл, спираючись на основні завдання, окреслені освітньою реформою.

\section{2. МЕТОДИ ДОСЛІДЖЕННЯ}

Під час дослідження використовувались такі методи: порівняльний педагогічний аналіз джерел, державних освітніх документів, установчих документів Європейського Союзу, освітніх установчих документів Великої Британії; систематизація і класифікація відібраного фактичного матеріалу; узагальнення досвіду Великої Британії з оцінювання ІК-компетентності вчителів, директорів та адміністраторів шкіл. Дослідження проводилося у рамках науково-дослідної роботи «Оцінювання інформаційнокомунікаційної компетентності суб'єктів навчального процесу системи загальної середньої освіти в умовах інтеграції України до європейського освітнього простору» (реєстраційний номер 0114U002196). 


\section{3. РЕЗУЛЬТАТИ ДОСЛІДЖЕННЯ}

У документі Свропейської Комісії "Підтримка професії вчителя" [7] відзначається, що відсутність чітких уявлень щодо очікування суспільства від викладачів ускладнює гарантованість впровадження стандартів високої якості для всіх шкіл, негативно впливає на відношення і розвиток професії вчителя, ускладнює визначення вимог у професійних стандартах, які б відповідали безпосередньо системам освіти країн, а також були спільними для всіх країн Європейського Союзу, включаючи працевлаштування і розвиток особистості. Таким чином, держави-члени ЄС визнають необхідність створення рамки компетентностей вчителів, яка чітко визначає знання, вміння і навички вчителів і може бути використана для:

- визначення результатів навчання відповідно до програм з педагогічної освіти,

- визначення критеріїв для набору та відбору викладацького складу,

- оцінювання потреб учителів для підвищення свого кваліфікаційного рівня,

- організації навчання для професійного розвитку вчителів,

- підтримки вчителів у розвитку своїх компетентностей протягом всієї кар'єри.

Освітня реформа, яка проводиться 32014 року, спрямована на поглиблене вивчення комп'ютерних наук, інформаційних технологій і підвищення рівня цифрової грамотності. Зважаючи на досить високі показники з використання IКТ вчителями Англії у навчальному процесі $(37,1 \%)$ порівняно з іншими країнами Свропи $(34 \%$ в СС в цілому) (Міжнародний огляд з викладання $i$ навчання, проведений Організацією економічного співробітництва і розвитку OECD 2014 року), у 2015 році Британська асоціація постачальників товарів для освіти BESA (British Educational Suppliers Association) констатувала, що 35\% вчителів, які викладали предмет IКТ, а зараз повинні викладати нововведений предмет Комп'ютинг не мають відповідної кваліфікації і підготовки, а 22\% ІТ-обладнання в школах $є$ неефектиним і застарілим. Урядом Великої Британії було визнано кризу цифрових вмінь та навичок. Для впровадження нових навчальних програм 3 Комп'ютингу у школах не вистачає кваліфікованих спеціалістів [8].

Комітет з цифрових навичок (Digital Skills Committee), який входить до Парламенту Великої Британії у своєму звіті перед Парламентом наголосив на великий вплив технологій, які дуже швидко розвиваються й удосконалюються, відповідаючи вимогам і потребам сучасного ринку праці. За прогнозами роботодавців і аналітиків протягом подальших 20 -ти років очікується автоматизація $35 \%$ робочих місць у країні, тому виникає нагальна потреба у набутті цифрових навичок потенційними працівниками. Політики з освіти звертають увагу на недостатню підготовку учнів 3 отримання необхідної цифрової грамотності, набуття достатнього рівня IKкомпетентності, на всіх рівнях освіти (початковій, середній, вищий). Було також задекларовано, що цифрова грамотність повинна мати таке жс значення $і$ бути базовим предметом, так само як математика і рідна мова.

Введення у школах Великої Британії предмета Комп'ютинг замість IКТ з вересня 2014 року було одним із перших кроків до зменшення розриву між рівнем отриманих учнями цифрових навичок $і$ вимогами сучасного ринку прачі краӥни. Для успішного проведення цього напряму освітньої реформи необхідна відповідна підготовка вчителів, директорів шкіл, сучасне обладнання школи, їх підключення до Інтернету. Було також зазначено, що не зважаючи на цифрову революцію близько 6 мільйонів (20\% населення деяких регіонів - дані 2015 року) громадян країни ніколи не користувалися мережею Інтернет, що є наслідком низького рівня забезпечення шкіл необхідним для цього обладнанням [2]. 
Для професійної діяльності у школах Великої Британії вчителі повинні отримати Кваліфікаційний статус вчителя - КСВ (Qualified Teacher Status - QTS), визнаний на правовому рівні, який окреслює відповідні обов'язкові компетентності вчителя. Починаючи з 1997 року КСВ присуджується вчителям, які успішно пройшли курс Початкової підготовки вчителів (Initial Teacher Training - ITT) в одному 3 акредитованих навчальних закладів.

Оцінювання рівня компетентності вчителя, який він повинен мати для присудження йому КСВ, визначаються трьома взаємопов'язаними критеріями (стандартами): професійна оцінка та практика, знання та розуміння, навчання. У кожному 3 цих стандартів окремим пунктом (вимогою) означено вміння ефективно використовувати IКТ, як для викладання свого предмету, так і для підтримки свого професійного розвитку. Окремим пунктом визначена вимога щодо складання кваліфікаційних тестів з ІКТ.

Усі курси і навчальні програми 3 Початкової підготовки вчителів, повинні відповідати навчальним планам і програмам, структурі, оцінюванню та загальним вимогам Департаменту освіти Великої Британії. Департамент освіти має право присуджувати Сертифікат (Postgraduate Certificate in Education - PGCE) після успішного проходження відповідних курсів післядипломної освіти.

Перевірка і нагляд за змістом курсів Початкової підготовки вчителів здійснюється Управлінням зі стандартів у галузі освіти (Office for Standards in Education - OFSTED), яке регулярно публікує інспекційні звіти на розгляд широкого загалу.

В Англії компетентною структурою, яка займається професійним розвитком вчителя, і має право присуджувати Кваліфікаційний статус вчителя є Національний коледж з викладання і лідерства (The National College for Teaching and Leadership) [9].

Зважаючи на високу планку ІК-компетентності, окреслену освітньою реформою, дослідження, проведені в Кембриджському університеті, показали, що певна кількість вчителів не має впевненості і навичок, необхідних для ефективного інтегрування IКТ у навчальний процес, яке б мотивувало студентів до навчання або подальшого опанування цифровими технологіями.

За останні три роки на підвищення рівня вмінь та навичок вчителів з IKT, їх адаптацію до нових навчальних програм з Комп'ютингу, а також підвищення рівня ІК-компетентності викладацького складу шкіл Департаментом освіти було виділено понад 4,5 млн фунтів стерлінгів, які розподілялися через такі організації як Комп'ютинг у школі (Computing at School), Національна асоціація з удосконалення компютерної освіти Naace (National Association for the Advancement of Computer Education) і Форум з комп'ютинг освіти Великої Британії (the UK Forum for Computing Education). Програми, які надаються вчителям через вище зазначені організації i мережі спрямовані не тільки на викладання нової програми Комп'ютинг, але й мають на меті підвищення рівня IК-компетентності вчителів з інших предметів [10].

Група експертів ЄС створила рекомендації для політиків в освіті Підтримка розвитку компетентності вчителя для покращення результатів навчання (Supporting teacher competence development for better learning outcomes ) [11]. На думку європейських фахівців оцінювання компетентностей вчителя $є$ важливим тому що, вчитель:

- оцінює, які компетентності йому необхідно розвивати далі;

- підтримує трансформацію в педагогічній культурі і практиці;

- підтримує визнання необхідних на його думку компетентностей;

- відіграє певну роль у забезпеченні та контролі якості навчання, що веде до його вдосконалення;

- сприяє розвитку довіри до викладачів. 
Оцінювання компетентностей учителів грунтується на загальному розумінні необхідності введення компетентнісного підходу в освіті, а також на національній рамці компетентностей вчителів, фокусуючись і розуміючи, що саме в даний час оцінюється.

Рамка оцінювання відображає рамку компетентностей i включає заходи (наприклад, використання портфоліо вчителя), які застосовуються у базовій підготовці вчителя, його вступу до професійної діяльності, а також під час підвищення кваліфікації, охоплюючи всі фази кар'єрного розвитку вчителя. Для того, щоб полегшити використання таких рамок для оцінювання розвитку компетентностей, a також мотивації вчителів щодо їх подальшого розвитку, визначаються різні рівні досягнень результатів для кожної компетентності.

Для створення системи оцінювання компетентностей рекомендовано визначити деякі ключові моменти, такі як:

$\checkmark$ що саме є у фокусі оцінювання - особистість, школа або система;

$\checkmark$ визначити взаємозв'язок між системами оцінювання і системою забезпечення якості;

$\checkmark$ чи спрямована система оцінювання на:

- підтримку розвитку вчителів (поточне - на постійній основі), або

- моніторинг їх досягнень (підсумкове - можливо, з визнанням вищого рівня компетентності, або рішенням по заробітній платі / нової посади); і

чи буде вона сфокусована на процесі або результатах розвитку компетентності.

При розробці системи оцінювання необхідно:

$\checkmark$ знайти правильний баланс між довірою і контролем;

$\checkmark$ бути справедливими, прозорим і вміти порівнювати (школи, регіони і освітні системи);

$\checkmark$ використовувати внутрішнє або зовнішнє оцінювання;

$\checkmark$ зосереджуватися на знаннях, навичках і відношенні вчителя;

$\checkmark$ ураховувати роль різних зацікавлених сторін в процесі оцінювання (наприклад, керівництво школи, колеги, учні, батьки, інспектори, органи освіти, місцеві та національні адміністративні системи, роботодавці та інші зацікавлені сторони);

$\checkmark$ ураховувати рівень оцінювання - наприклад, окремі особи або групи вчителів; шкільні установи і мережі; регіональний і системний рівень - національний або міжнародний рівень.

Інструменти $і$ методи, які задіяні в системах оцінювання можуть бути досить різноманітними і повинні обиратися і відповідати особливостям національних систем освіти.

Спираючись на вищезазначені рекомендації фахівців СС у 2015 році освітянами Великої Британії були розроблені рекомендації з аттестації вчителів і директорів шкіл, (Teacher's Appraisal Policy), що спрямовані на підтвердження рівнів їх кваліфікації, визначення недоліків у роботі, подальшу спрямованість на професійний розвиток [12].

Відповідно до вищезазначених рекомендацій, у підсумковому звіті з оцінювання професійної діяльності вчителів [12] оцінювання ІК-компетентності проводиться за шкалою від 4-х (найнижчий рівень) до 1-го (найвищий рівень) : 
Таблиия 1

\begin{tabular}{|c|l|}
\hline Рівні & \multicolumn{1}{|c|}{ Вимоги щодо використання навчальних ресурсів } \\
\hline 4 & $\begin{array}{l}\text { Інформаційно-комунікаційні технології або інтерактивні ресурси зовсім не } \\
\text { використовуються }\end{array}$ \\
\hline 3 & $\begin{array}{l}\text { Інформаційно-комунікаційні технології або інтерактивні ресурси } \\
\text { використовуються } \\
\text { компетентно (достатньо) }\end{array}$ \\
\hline 2 & $\begin{array}{l}\text { Інформаційно-комунікаційні технології або інтерактивні ресурси } \\
\text { використовуються творчо й ефективно з метою підтримки навчання учнів }\end{array}$ \\
\hline 1 & $\begin{array}{l}\text { Доцільне і вибіркове використання ІКТ та інтерактивних технологій } 3 \\
\text { метою підвищення мотивації, рівня навчальних досягнень учнів }\end{array}$ \\
\hline
\end{tabular}

Запропоновано такі методи оцінювання ІК-компетентності:

поточне оцінювання:

- регулярні зустрічі з директором або іншими співробітниками,

- самооцінка,

- створення критично налаштованих груп (колеги), для оцінювання i обговорення досягненнь,

- оцінка власних доягнень колегами,

- індивідуальні плани розвитку,

- спостереження колег за проведенням уроку,

- аналіз відео уроків,

- звіти,

- портфоліо,

- дослідження діяльності (самоаналіз),

підсумкове оцінювання:

- іспити,

- тестування,

- спостереження за процесом викладання,

- мікро навчання (відповідно створеного плану саморозвитку)

- аналіз відео уроків,

- портфоліо.

У вересні 2016 року, базуючись на Стандарті для вчителів (Teachers' standards), Стандарті для директорів шкіл (National Standards of Excellence for Head Teachers'), a також державних регулюючих документах, вищезазначених документах ЄС, було розроблено і рекомендовано «Модель для атестації штату і політики 3 професійної кваліфікації школи» (Model staff appraisal and capability policy)[13]. Розроблений документ спрямований на чітке і послідовне оцінювання ефективності роботи вчителів, директорів, адміністрації шкіл, виявлення їх потреб для свого подальшого розвитку у контексті підвищення рівня навчання і розвитку школи. Відповідно до цього документу атестацію вчителів, адміністрації школи проводить директор школи, який може залучити до цього процесу представників державних органів освіти. Директора школи мають право атестувати вищі державні освітні структури, які призначають його на цю посаду i представники інспекції, за підтримки кваліфікованого, досвідченого зовнішнього консультанта, у найкращому випадку, хто мав досвід керівництва в подібній школі і який був призначений Керуючим органом освіти з цією метою.

3 огляду на те, що подальший розвиток системи освіти Великої Британії спрямований на повну автономію, «академізацію» всіх початкових і середніх шкіл, 
яка повинна завершитися до 2022 року [8], методи та інструменти з оцінювання IКкомпетентності кожна школа обирає самостійно.

Зважаючи на цілі, окреслені освітньою реформою 2014 року, однією з яких є підвищення рівня ІК-компетентності громадян країни починаючи 3 початкової школи, вимагає від викладацького складу постійного удосконалення своїх вмінь i навичок з використання ІКТ, підвищує їх рівень ІК-компетентності. Результат атестації професійної діяльності як вчителя, так і директора школи ураховує наявність сертифікатів, які підтверджують проходження відповідних курсів, більшість $з$ яких проводиться онлайн, і демонструють не тільки набуті вміння та навички, але й підтверджують бажання i прагнення до саморозвитку, самоудосконалення з використання ІКТ у навчальному процесі.

Кількість таких курсів постійно збільшується, але на цей час можна зазначити декілька найбільш поширених, рекомендованих Департаментом освіти.

Atomic Learning [14], онлайн курси засновані у 2000 році групою викладачів 3 IКТ. Курсами користуються і проходять навчання мільйони студентів більш ніж у 45 країнах світу. Навчання сфокусоване на практичному застосуванню IКТ в освіті для студентів, викладачів з різних предметів, шкільного персоналу. Основні напрями:

- Підготовка з IКТ для сучасного навчання - використання IКТ під час проведення уроків, навчальних проектів, інструменти 3 оцінювання вмінь та навичок використання ІКТ.

- Розвиток штату викладачів - підготовка персоналу школи до набуття i використання технологічних навичок під час і після уроку, безперервний розвиток своєї професійної діяльності використовуючи ІКТ, розвиток критичного мислення.

- Інтегровані інструменти $i$ підтримка для підвищення ефективності навчання. У розділі розміщена велика підбірка цифрових інструментів для забезпечення учнів сучасним навчанням 3 миттєвим доступом до різних навчальних онлайн ресурсів.

Запропоновано декілька різних варіантів онлайн оцінювання, які адаптовані до вимог шкіл, коледжів, університетів, включаючи оцінювання стандартів ISTE, базове само оцінювання, базове оцінювання навичок 3 комп'ютерної грамотності i популярних програмних додатків розрахованих на учнів і вчителів.

Очінювання стандартів ISTE сфокусовано на застосуванні технологій. Інструментарій допомагає школам, коледжам, університетам визначити основні напрями подальшого розвитку вчителя i спрямувати учнів до відповідного використання технологій, коли це необхідно.

Оиінювання технологічних навичок - можливість пройти онлайн підготовку 3 комп'ютерної грамотності та популярних додатків Microsoft@ Office (140 курсів на цей час). Після кожного курсу проводиться оцінювання навчальних досягнень, ІКкомпетентності вчителя.

Самооцінка - швидкий і простий онлайн інструмент, який надає можливість перевірити себе, наскільки ви опанували тими чи іншими технологіями, використовуючи для цього відповідні інструменти.

Усі вищезазначені курси і проведення процесу оцінювання можливо тільки після реєстрації на сайті, деякі сервіси, послуги і представлені продукти є платними. Після проходження курсів видаються Сертифікати.

Future Learn [15], кількість слухачів досягла 4,998,344 охоплюючи різні континенти і країни світу, дуже швидко розвиваються і стають популярними. У їх розробках беруть участь 103 освітні інституції (університети, освітні міжнародні організації, бізнес структури, провайдери освітніх послуг) з усього світу. 
Курси постійно оновлюються, охоплюючи різні напрями за такими категоріями: Бізнес і менеджмент; Креативне мистецтво і медіа; Здоровя і психологія; Історія; Мови і культури; Право; Література; Природа та оточуюче середовище; Онлайн і цифровий; Політика і сучасний світ; Наука, математика і технології; Спорт і відпочинок; Навчання і викладання.

Існують як базові, так і поглиблені програми з викладання різних предметів. Кожен вчитель може, зареєструвавшись, пройти один 3 таких безкоштовних курсів i отримати відповідний сертифікат.

Інститут TES (TES - Times Educational Supplement) [16] найбільш швидко зростаюча цифрова спільнота, а також найбільша професійна мережа вчителів (більш ніж 7,7 млн. зареєстрованих користувачів онлайн в 197 країнах) спрямована на розвиток та удосконалення професійної діяльності вчителя й адміністрації шкіл впродовж їх роботи у навчальному закладі. У процесі підготовки використовується онлайн і змішане навчання, охоплює початкову підготовку вчителів і безперервний професійний розвиток, включає курси для вчителів-предметників. Проходження програм дозволяє отримати Кваліфікаційний статус вчителя, а також Сертифікат 3 післядипломної освіти вчителя. У програмах окремим пунктом окреслених цілей визначено: Впевнене використання нових технологій, маючи на увазі впровадження інноваційних освітніх технологій не тільки у навчальний процес, а й у адміністрування школою.

Мережа педагогічної майстерності в галузі комп'ютерних наук (Network of Teaching Excelence in Computer Science - NoE) [17] - національна спільнота професійної практики. Це співтовариство $\epsilon$ партнерством між школами, університетами, IT-роботодавцями і професійними організаціями. Створена у рамках мережі Комп'ютинг у школі, будучи частиною Британського комп'ютерного товариства BCS (British Computer Society - BCS), яке разом з Департаментом освіти Великої Британії надає фінансову підтримку.

Навчальні програми і курси з безперервного професійного розвитку включають тренінги, підтримку тьютора, моніторинг та оцінювання отриманих знань, співпрацю 3 колегами.

Мережа підтримується цілою низкою партнерів, таких, як Департамент освіти (DfE), Microsoft, Google, Рада професорів і керівників з Компютингу, OCR i AQA.

Національна асоціація директорів шкіл (The National Association of Head Teachers - NAHT) [18] надає можливість пройти курси 3 підвищення кваліфікації керівників, адміністрації шкіл. Курси спрямовані на розвиток професійних навичок, охоплюючи такі напрями, як менеджмент школи, контроль якості, вплив освітньої політики і практики на розвиток школи, впровадження інноваційних технологій у процес адміністрування школою тощо.

Попри вищезазначені онлайн курси як інструмент використовуються віртуальне середовище Khan Academy, а також YouTube, Twitter, Skype Classroom, Google+, Google Apps тощо.

Рішення про проходження такого курсу вчитель приймає або сам відповідно свого особистого плану професійного розвитку, або такий курс може бути запропонований атестаційною комісією після проходження атестації.

Сертифікати, отримані після закінчення онлайн курсів, ураховуються під час проведення атестації професійної діяльності вчителя, директора школи. До уваги беруться не тільки отримані відповідні вміння та навички, але й їх вдале, обізнане впровадження у навчальний процес, що за результатом атестації впливає на зміну заробітній платні і кар'єрному зростанні. 


\section{4. ВИСНОВКИ ТА ПЕРСПЕКТИВИ ПОДАЛЬШИХ ДОСЛІДЖЕНЬ}

За результатами аналізу поступового впровадження освітньої реформи у Великій Британії можна зробити тіак висновки:

- освітня реформа значно підвищує рівень цифрової грамотності учнів, що значно залежить від відповідної підготовки вчителів, їх рівня ІКкомпетентності;

- оцінювання ІК-компетентності вчителів і директорів шкіл відбувається відповідно до рекомендацій фахівців СС, Стандартів для вчителів, Стандартів для директорів шкіл, а також «Моделі для атестації штату і політики 3 професійної кваліфікації школи», розробленої і рекомендованої освітніми інституціями разом з Департаментом освіти Великої Британії;

- відповідно до освітньої політики щодо автономії шкіл, методи та інструменти 3 оцінювання ІК-компетентності вчителів, директорів шкіл кожний навчальний заклад обирає самостійно, керуючись державними, регулюючими рекомендаціями.

За останні роки система освіти Великої Британії зробила суттєві кроки щодо створення цілісної сучасної системи оцінювання рівня сформованості IКкомпетентності, а також були створено можливості для підвищення кваліфікації учителів у напряму впровадження IКТ в навчання. Процес реформування освіти Великої Британії продовжується. Методи та інструменти оцінювання ІКкомпетентності вчителів, адміністраторів та директорів шкіл знаходяться у процесі широкого обговорення освітянською спільнотою. Вважаємо подальше дослідження цієї тематики актуальним для розвитку сучасної української освіти.

\section{СПИСОК ВИКОРИСТАНИХ ДЖЕРЕЛ}

1. ICT Competency Standard for Teachers and Institutional Strategy for Teacher Training on ICT-pedagogy Integration [Електронний pecypc]. http://siteresources.worldbank.org/EDUCATION/Resources/UNESCO-Miao_TeacherTrainingonICTpedagogyIntegration.pdf

2. The Digital Skills Committee [Електронний ресурс] / Офіційний сайт Парламенту Великої Британії. - Режим доступу : http://www.parliament.uk/business/committees/committees-a-z/lords-select/digitalskills-committee/news/report-published/

3. Council conclusions of 12 May 2009 on a strategic framework for European cooperation in education and training ('ET 2020') 2009/C 119/02 / EUR-lex access to European Union Law [Електронний ресурс]. - Режим доступу : $\quad$ д content/EN/ALL/:ELX_SESSIONID=hbyVJK0CTK1WGDGKnG4b18Tp2T2mwwknj38V6yqn181BD6N wXQBy!-1095106434?uri=CELEX:52009XG0528(01).

4. Digital Agenda for Europe (DAE) [Електронний ресурс] / European Commission oficial site. — Режим доступу : http://ec.europa.eu/digital-agenda/en/digital-agenda-europe

5. Key Competences for Lifelong Learning, 2006) [Електронний ресурс] / сайт Європейського Союзу. - Режим доступу

http://europa.eu/legislation_summaries/education_training_youth/lifelong_learning/c11090_en.htm

6. European Qualifications Framework for Lifelong Learning, 2008 [Електронний ресурс] / Сайт Європейського Союзу.
http://europa.eu/legislation_summaries/internal_market/living_and_working_in_the_internal_market/c11 104_en.htm

7. Supporting teacher competence development [Електронний ресурс] / Сайт Свропейського Союзу. Режим доступу :http://ec.europa.eu/dgs/education_culture/repository/education/policy/school/doc/teachercomp_en.pdf

8. Summery of the Education and Adoption Act 2016 [Електронний ресурс] / Офіційний сайт Парламенту Великої Британії. - Режим доступу: http://services.parliament.uk/bills/201516/educationandadoption.html. 
9. Miniversion: The UK teacher competences and requirements [Електронний ресурс]. — Режим доступу:www.teacherqualitytoolbox.eu/uploads/mini_version_tq_uk.doc

10. Didital skills in schools [Електронний pecypc] / Офіційний сайт Парламенту Великої Британії. Режим доступу :http://www.publications.parliament.uk/pa/cm201617/cmselect/cmsctech/270/27006.htm

11. Підтримка розвитку компетентності вчителя для покращення результатів навчання (Supporting teacher competence development for better learning outcomes [Електронний ресурс] / сайт Європейського Союзу. - Режим доступу: http://ec.europa.eu/dgs/education_culture/repository/education/policy/school/doc/teachercomp_en.pdf)

12. Teacher's Appraisal Policy 2015 2016 [Електронний ресурс] / REAch2 Academy Trust. - Режим доступу: http://reach2.org/about-us/how-we-work/

13. Model staff appraisal and capability policy [Електронний ресурс] / сайт Департаменту освіти Великої Британії. - Режим доступу : https://www.gov.uk/government/publications/teacher-appraisal-andcapability-model-policy

14. Atomic Learning [Електронний pecypc]. - Режим доступу: https://wwwq.atomiclearning.com/uk/assessment

15. Future Learn [Електронний ресурс]. - Режим доступу: https://www.futurelearn.com

16. Інститут TES [Електронний ресурс]. — Режим доступу: https://www.tes.com/institute/schooldirect-itt-programme

17. Мережа педагогічної майстерності в області комп'ютерних наук (Network of Teaching Excelence in Computer Science) [Електронний ресурс] / сайт Британського комп'ютерного товариства BCS. - Режим доступу: http://academy.bcs.org/content/network-teaching-excellence-computer-science

18. Національна асоціація директорів шкіл (The National Association of Head Teachers) [Електронний pесурс]. — Режим доступу: http://www.naht.org.uk/welcome/about-naht/history

Матеріал надійшов до редакиї 07.12.2016 p.

\title{
ВЫСОКИЙ УРОВЕНЬ ИК-КОМПЕТЕНТНОСТИ УЧИТЕЛЯ - ЗАЛОГ ПОВЫШЕНИЯ ЦИФРОВОЙ ГРАМОТНОСТИ УЧАЩИХСЯ (ОПЫТ ВЕЛИКОБРИТАНИИ)
}

\author{
Малицкая Ирина Дмитриевна \\ старший научный сотрудник Отдела компаративистики информационно-образовательных инноваций \\ Институт информационных технологий и средств обучения НАПН Украины, г. Киев, Украина \\ Irina_Malitskaya@mail.ru
}

\begin{abstract}
Аннотация. В статье рассматриваются подходы к оцениванию ИК-компетентности учителя, администратора и директора школы Великобритании. Отмечается, что процесс оценивания опирается на государственные стандарты, регулирующие документы, а также «Модель для аттестации штата и политики профессиональной квалификации школы», разработанной и рекомендованной образовательными учреждениями вместе с Департаментом образования Великобритании. Описанны методы оценивания ИКкомпетентности учителя, а также наиболее признанные инструменты: Atomic Learning, Future Learn, TES Global, сети Computer at School и Network of Excellence и др.
\end{abstract}

Ключевые слова: информационные и коммуникационные технологии; ИКкомпетентность; учитель; директор школы; оценивание; система образования Великобритании; зарубежный опыт.

\section{HIGH LEVEL OF TEACHER'S IC-COMPETENCY - KEY TO IMPROVING THE STUDENTS' DIGITAL LITERACY (GREAT BRITAIN EXPERIENCE)}

\section{Iryna D. Malytska}

senior researcher of the Comparative Studies Department for Information and Education Innovations Institute of Information Technologies and Learning Tools of NAES of Ukraine, Kyiv, Ukraine Irina_Malitskaya@mail.ru 


\begin{abstract}
In the article the approaches to the teacher's, administrator's and head teacher's ICcompetency assessment in Great Britain are considered. It is noted that the assessment process is based on the national standards, regulatory documents, as well as the "Model staff appraisal and capability policy", developed and recommended by the educational institutions together with the Department of Education of Great Britain. There are described methods for the teacher's ICcompetency assessment, as well as the most recognized tools: Atomic Learning, Future Learn, TES Global, Network Computer at School and the Network of Excellence and etc.
\end{abstract}

Keywords: information and communication technologies; IC- competency; teacher; head teacher; assessment; education system of Great Britain; foreign experience.

\title{
REFERENCES (TRANSLATED AND TRANSLITERATED)
}

1. ICT Competency Standard for Teachers and Institutional Strategy for Teacher Training on ICTpedagogy Integration [online]. - $\quad$ Available from : http://siteresources.worldbank.org/EDUCATION/Resources/UNESCO-Miao_TeacherTrainingonICTpedagogyIntegration.pdf (in English).

2. The Digital Skills Committee [online] / UK Parliament official site. - Available from: http://www.parliament.uk/business/committees/committees-a-z/lords-select/digital-skillscommittee/news/report-published/ (in English).

3. Council conclusions of 12 May 2009 on a strategic framework for European cooperation in education and training ('ET 2020') 2009/C 119/02 / EUR-lex access to European Union Law [online]. Available from: http://eur-lex.europa.eu/legalcontent/EN/ALL/;ELX_SESSIONID=hbyVJK0CTK1WGDGKnG4b18Tp2T2mwwknj38V6yqn181B D6NwXQBy!-1095106434?uri=CELEX:52009XG0528(01) (in English)..

4. Digital Agenda for Europe (DAE) [online] / European Commission official site. — Available from: http://ec.europa.eu/digital-agenda/en/digital-agenda-europe (in English).

5. Key Competences for Lifelong Learning, 2006) [online] / European Union official site. — Available from:

http://europa.eu/legislation_summaries/education_training_youth/lifelong_learning/c11090_en.htm (in English).

6. European Qualifications Framework for Lifelong Learning, 2008 [online] / European Union official site. - - Available from: http://europa.eu/legislation_summaries/internal_market/living_and_working_in_the_internal_market/ c11104_en.htm (in English).

7. Supporting teacher competence development [online] / European Union official site. _ Available from:http://ec.europa.eu/dgs/education_culture/repository/education/policy/school/doc/teachercomp_e n.pdf (in English).

8. Summery of the Education and Adoption Act 2016 [online] / UK Parliament official site. — Available from: http://services.parliament.uk/bills/2015-16/educationandadoption.html (in English)..

9. Miniversion: The UK teacher competences and requirements [online]. — Available from:www.teacherqualitytoolbox.eu/uploads/mini_version_tq_uk.doc (in English).

10. Didital skills in schools [online] / UK Parliament official site. _ Available from:http://www.publications.parliament.uk/pa/cm201617/cmselect/cmsctech/270/27006.htm (in English).

11. Supporting teacher competence development for better learning outcomes [online] / European Union $\begin{array}{lllllll}\text { official } & \text { site. } & \text { - } & \text { Available } & \text { from: }\end{array}$ http://ec.europa.eu/dgs/education_culture/repository/education/policy/school/doc/teachercomp_en.pdf ) (in English).

12. Teacher's Appraisal Policy 2015\2016 [online] / REAch2 Academy Trust. - Available from: http://reach2.org/about-us/how-we-work/ (in English).

13. Model staff appraisal and capability policy [online] / Department of Education UK. — Available from: https://www.gov.uk/government/publications/teacher-appraisal-and-capability-model-policy (in English).

14. Atomic Learning [online]. — Available from: [https:/www-q.atomiclearning.com/uk/assessment (in English).

15. Future Learn [online]. — Available from: https://www.futurelearn.com (in English).

16. Інститут TES [online]. — Available from: https://www.tes.com/institute/school-direct-ittprogramme (in English). 
17. Network of Teaching Excelence in Computer Science [online] / British Academy of Computer Science BCS. - Available from: http://academy.bcs.org/content/network-teaching-excellencecomputer-science (in English).

18. The National Association of Head Teachers [online]. — Available from: http://www.naht.org.uk/welcome/about-naht/history (in English).

Conflict of interest. The author has declared no conflict of interest.

\section{$(\mathrm{Cc})$ BY-NC-SA}

This work is licensed under Creative Commons Attribution-NonCommercial-ShareAlike 4.0 International License. 